Bangl. J. Vet. Med. (2008). 6 (1): 87-92

\title{
EVALUATION OF SANITARY QUALITY OF GOAT MEAT OBTAINED FROM SLAUGHTER YARDS AND MEAT STALLS AT LATE MARKET HOURS
}

\author{
M. A. Haque, M. P. Siddique*, M. A. Habib, V. Sarkar and K. A. Choudhury
}

Department of Microbiology and Hygiene, Faculty of Veterinary Science, Bangladesh Agricultural University, Mymensingh-2202, Bangladesh

*Corresponding author's e-mail address: mpsiddique77@gmail.com

\begin{abstract}
The microbiological investigation was conducted to determine the level of contamination of goat meat processed by butchers in slaughter yards and meat stalls and also at different body regions such as neck, brisket and thigh during the period of July to November 2007 in the Department of Microbiology and Hygiene, Bangladesh Agricultural University (BAU), Mymensingh, Bangladesh. A total number of 36 meat samples were collected equally from three slaughter yards and meat stalls namely Koshaibari, Mymensingh town and BAU campus, each containing 12 samples. Out of these 12 samples, four samples from brisket region, four samples from neck region, and four samples from thigh region were taken. After collection, bacteriological analysis of the samples were performed to asses the selected microbial attributes such as TVC, TCC and TSC in goat meat cuts of different sources by using Plate Count (PC) agar, MacConkey (MC) agar and Staphylococcal Media (SM-110) medium to find out the sanitary quality of goat meat. The mean values of TVC on slaughter yards and meat stalls were $\log 6.03$ and $\log 6.53$ respectively, whereas the TCC showed $\log 4.85$ and $\log 3.82$ respectively and that of TSC were 3.31 and 3.82 respectively. The mean values of TVC in brisket, neck and thigh regions of slaughter yards were $\log 6.11, \log 6.01, \log 6.31$ and in meat stalls were $\log 6.48$, $\log 6.30, \log 6.84$ respectively, whereas the TCC values of slaughter yards showed $\log 4.77, \log 4.36, \log 5.12$ and meat stalls $\log 4.94, \log 4.68, \log 5.42$ respectively. In case of TSC values, the mean values were $\log 3.83, \log 3.07$, $\log 4.06$ and $\log 3.96, \log 3.37, \log 4.22$ respectively. The result demonstrates the fact that the unhygienic and poor sanitary conditions under which the meat and meat products are handled and processed are not acceptable from sanitary point of view. The statistical analysis showed that TVC and TCC obtained from meat samples of different markets and different regions of the carcass exhibited regional variation significantly $(\mathrm{P}<0.01)$, whereas TSC did not present any remarkable regional variation. A significant correlation in TVC and TCC was found $(\mathrm{P}<0.01)$ and similar correlation was also recorded in TCC and TSC $(\mathrm{P}<0.01)$, but it is interesting to note that there was no significant correlation in between TVC and TSC.
\end{abstract}

Key words: Goat meat, TVC, TCC, TSC, sanitary quality.

\section{INTRODUCTION}

Goat is the animal of the developing countries where more than 95\% of goats are reared in Asia and Africa (Chowdhury and Mutalib, 2003). At present, the approximate number of goats is 33.5 millions in Bangladesh (Samad, 2001). As a source of animal protein, goat meat has for long occupied a special place in the diet for a variety of reasons including taste preference, prestige, religion, tradition and availability, in almost all the communities of the country with the nutritional aspects being included more recently (Dhanda, 2001). Meat was the first important food that met up the hunger of ancient people living in cave (Johanson et al., 1983). It plays a very vital role in keeping the human body strong in order to provide energy, health and vigor (Rahman, 2000). But, microorganisms present in meat may be harmful for human and may cause spoilage and may be used as indicator organisms. Many researchers have isolated and identified heterogeneous types of microflora from fresh meat (Brahmbhatt and Anjaria, 1991). 
The public due to unawareness and due to non-enforcement of laws, many a time, buy meat which cannot ensure protection to consumers from the effect of potential danger of inferior meat (Hassall, 1995). In view of the microbial implication in handling, slaughtering, dressing, processing and distribution of meat and meat products which may endanger human health, the study was undertaken to determine the extent of microbial contamination of goat meat of brisket, neck and thigh obtained from slaughter yards and from meat stalls at late market hours and to asses the selected microbial attributes such as total viable bacterial count (TVC), total coliform count (TCC) and total staphylococcal count (TSC) in goat meat cuts of different sources. Thereby, the sanitary quality of goat meat sold in meat stalls was evaluated.

\section{MATERIALS AND METHODS}

\section{Sample collection and transportation}

A total number of 36 meat samples were collected equally from three slaughter yards and meat stalls namely Koshaibari, Mymensingh town and Bangladesh Agricultural University (BAU) campus, each containing 12 samples. Out of these 12 samples, four samples from brisket region, four samples from neck region, and four samples from thigh region were taken. The samples include raw meat and swab samples from goat meat. Samples were collected aseptically in sterile containers and brought to the laboratory within 30-45 minutes using ice box. After collection, bacteriological analysis of the samples were performed to asses the selected microbial attributes such as TVC, TCC and TSC in goat meat cuts of different sources by using Plate Count (PC) agar, MacConkey (MC) agar and Staphylococcal Media (SM-110) medium to find out the sanitary quality of goat meat.

\section{Raw goat meat samples}

Raw meat samples of goat meat were collected directly from the carcass and from the retail hanging display of butchers. A quantity of about 500 gms of meat cut samples were collected from the different regions of the carcass, such as brisket, neck and thigh. Individual sample is minced and a quantity of 50 gms was transferred into sterile containers containing $450 \mathrm{ml}$ of $0.1 \%$ peptone water. A homogenized suspension was made in a sterile blender. Thus 1:10 dilution of the sample was obtained. Later on using Whirly mixture machine different serial dilutions ranging from $10^{-2}-10^{-6}$ were prepared according to the recommendation of International Organization for Standardization (ISO, 1995). In another experiment, meat samples were collected at delayed market hours. All these samples were subjected to bacteriological analysis such as determination of TVC, TCC and TSC using the PC agar, MC agar and SM-110 respectively.

\section{Swab samples}

Cotton swabs were used in this study. The swabs were prepared using non-absorbent cotton wool, which is wound to a length of four centimeter and a thickness of 1 to 1.5 centimeter on wooden sticks. They were placed in glass tubes which were then plugged and sterilized. The swabs were moistened before use with sterile $0.1 \%$ peptone water. These were rubbed firmly over the surface using parallel strokes with slow rotation. The surface to be examined was swabbed twice using parallel strokes at right angles to the first strokes. The predetermined area to be swabbed was chosen and template of ten square centimeter area was placed over the predetermined area. Care was taken to swab the whole of the predetermined area. After swabbing, the swabs were transferred to the respective tubes containing the 5 milliliter of sterile $0.1 \%$ peptone water. The swabs were agitated up and down in the tubes to assist the rinsing of bacteria from the surface of the swabs.

\section{Enumeration of TVC, TCC and TSC}

For the determination of TVC, $0.1 \mathrm{ml}$ of each ten-fold dilution was transferred and spread on triplicate NA agar using a sterile pipette for each dilution. The diluted samples were spread as quickly as possible on the surface of the plate with a sterile glass spreader. One sterile spreader was used for each plate. The plates were then kept in an incubator at $35^{\circ} \mathrm{C}$ for $24-48$ hours. Following incubation, plates exhibiting 
30-300 colonies were counted. The average number of colonies in a particular dilution was multiplied by the dilution factor to obtain the TVC. For the determination of total coliform, TVC method was employed. For TCC method MC agar plates were used as above. For the determination of TSC, the procedures of sampling, dilution and streaking were similar to those followed in TVC of bacteria. Only in case of staphylococcal count, SM-110 was used. The calculation for TSC was similar to that of TVC.

\section{Statistical analysis}

The data on TVC, TCC and TSC obtained from the study of carcass surfaces and carcass regions collected from different butchers retail meat sale stalls and were analyzed in completely randomized design (CRD) using computer package MSTAT-C (Freed, 1992). Correlation between TVC, TCC and TSC were evaluated.

\section{RESULTS AND DICUSSION}

\section{Total viable count}

The result presented in Table 1 reveals that the mean value of the TVC of goat meat processed at slaughter yards of Koshaibari, Mymensingh Town and BAU campus was log 6.03 and mean TVC value from delayed sample of goat meat sold in meat stalls was log 6.53 (Table 1). In another study, the microbial load in meat samples of different body regions of goat meat carcasses was determined. The mean values of TVC in brisket, neck and thigh of goat meat processed at slaughter yards were $\log 6.11, \log 6.01$ and $\log 6.31$ respectively and $\log 6.48, \log 6.30$ and $\log 6.84$ respectively in delayed sample of goat meat sold in meat stalls (Table 2). The mean values of TVC of goat meat processed at slaughter yards is log 6.03. Whereas the goat meat sold in meat stalls is $\log 6.53$, a remarkable increase in bacterial population. This result has revealed that massive contaminations occur but there is more or less uniformity in bacterial load on carcass surfaces. However the lower counts on external surfaces are probably due in part to the fat layer which tends to reduce the amount of unbound moisture available for the growth or survival of microorganism (Jay, 1978 and Lasta et al., 1992) and also due to more exposure to washing. Hassall (1995) studied the microbial content of fresh meat from the time of slaughter to the retail outlet and concluded that the bacterial count increased tremendously by the time the carcasses were received by the store.

Table 1. Microbial load of goat meat, processed in slaughter yards (fresh meat sample) and sold in meat stalls (Delayed meat sample)

\begin{tabular}{|c|c|c|c|c|c|c|c|}
\hline \multirow{2}{*}{$\begin{array}{l}\text { Place of } \\
\text { collection }\end{array}$} & \multirow{2}{*}{$\begin{array}{l}\text { Sample } \\
\text { no. }\end{array}$} & \multicolumn{2}{|l|}{ TVC/gm } & \multicolumn{2}{|l|}{ TCC/gm } & \multicolumn{2}{|l|}{ TSC/gm } \\
\hline & & $\begin{array}{l}\text { Slaughter } \\
\text { yards }\end{array}$ & $\begin{array}{l}\text { Meat } \\
\text { stalls }\end{array}$ & $\begin{array}{l}\text { Slaughter } \\
\text { yards }\end{array}$ & $\begin{array}{l}\text { Meat } \\
\text { stalls }\end{array}$ & $\begin{array}{l}\text { Slaughter } \\
\text { yards }\end{array}$ & $\begin{array}{l}\text { Meat } \\
\text { stalls }\end{array}$ \\
\hline \multirow[t]{4}{*}{ Koshaibari } & 1 & 6.19 & 7.52 & 5.25 & 5.76 & 4.05 & 4.08 \\
\hline & 2 & 6.11 & 6.72 & 5.50 & 5.78 & 3.79 & 3.49 \\
\hline & 3 & 6.18 & 6.01 & 5.09 & 5.46 & 3.98 & 4.06 \\
\hline & 4 & 6.16 & 7.20 & 5.00 & 5.30 & 3.49 & 3.50 \\
\hline \multirow[t]{4}{*}{ BAU Campus } & 5 & 5.95 & 6.39 & 5.41 & 5.19 & 3.48 & 3.79 \\
\hline & 6 & 6.24 & 6.28 & 5.94 & 5.18 & 3.06 & 4.57 \\
\hline & 7 & 5.98 & 7.64 & 4.77 & 4.72 & 3.13 & 3.65 \\
\hline & 8 & 6.17 & 6.49 & 4.97 & 4.61 & 3.85 & 3.86 \\
\hline \multirow[t]{4}{*}{ Mymensingh } & 9 & 5.97 & 5.69 & 4.56 & 4.57 & 2.59 & 3.04 \\
\hline & 10 & 5.79 & 5.99 & 4.09 & 4.55 & 2.61 & 4.87 \\
\hline & 11 & 5.81 & 5.94 & 4.06 & 4.49 & 2.63 & 3.10 \\
\hline & 12 & 5.85 & 6.49 & 4.53 & 4.82 & 3.06 & 3.79 \\
\hline Mean & & 6.03 & 6.53 & 4.85 & 5.03 & 3.31 & 3.82 \\
\hline
\end{tabular}

All counts are expressed in logarithms . 
The results as evidenced in Table 2 showed the TVC values per gram of meat sample from different body regions such as brisket, neck, and thigh were $\log 6.48$, log 6.30 and $\log 6.84$ respectively. Similar observations were also noted by Jay (1978); Hassall (1995); Sinha and Mandal (1977) where they found the microbial load in goat meat samples of neck muscle and thigh muscle to be $28.6 \times 10^{5}$ and $6.6 \times 10^{5} / \mathrm{gm}$ respectively. In another investigation Rahman et al., (1979) reported TVC per gram of market meat samples of neck, forelimb, and hindlimb as $6.45 \times 10^{6}, 10.4 \times 10^{6}$ and $31.4 \times 10^{6}$ respectively. Although Sankaran et al. (1975) obtained lower microbial load with a total count of $7.7 \times 10^{5}$ to $7 \times 10^{6}$ per gm, but Ingram and Roberts (1987) observed higher count of $3.5 \times 10^{7} / \mathrm{gm}$ of meat. Since the safety, shelf life and keeping of fresh foods are related to microbial content, microbiological standards have been proposed for a variety of foods. Such standards usually specify a total count as well as indicator maxima (Hubbert et al., 1996 and Rahman et al., 1997). ICMSF (1985) recommended that the general viable count of fresh meat tissue should be less than log 6.00 per gram. TVC found in meat samples of the present study indicated a remarkable increase. Bolton (1996) and Hassall (1995) similarly led to the opinion that meat production in Bangladesh takes place in a very disorganized way, but due to the non availability of cold chain the product is sold and consumed without delay, as a result massive contamination if there is, cannot enhance meat deterioration and the threat which may arise cannot endanger the health of consumers.

Table 2. General viable counts of different body regions of goat meat carcass processed in slaughter yards (fresh) and meat cuts sold in meat stalls (Delayed)

\begin{tabular}{|c|c|c|c|c|c|c|c|}
\hline \multirow{2}{*}{$\begin{array}{l}\text { Region of } \\
\text { carcasses }\end{array}$} & \multirow{2}{*}{$\begin{array}{l}\text { Sample } \\
\text { numbers }\end{array}$} & \multicolumn{2}{|l|}{ TVC/gm } & \multicolumn{2}{|l|}{ TCC/gm } & \multicolumn{2}{|l|}{ TSC/gm } \\
\hline & & $\begin{array}{l}\text { Slaughter } \\
\text { yards }\end{array}$ & $\begin{array}{l}\text { Meat } \\
\text { stalls }\end{array}$ & $\begin{array}{l}\text { Slaughter } \\
\text { yards }\end{array}$ & $\begin{array}{l}\text { Meat } \\
\text { stalls }\end{array}$ & $\begin{array}{l}\text { Slaughter } \\
\text { yards }\end{array}$ & $\begin{array}{l}\text { Meat } \\
\text { stalls }\end{array}$ \\
\hline \multirow[t]{5}{*}{ Brisket } & 1 & 6.11 & 6.46 & 4.91 & 5.12 & 3.79 & 3.91 \\
\hline & 2 & 6.07 & 6.72 & 4.77 & 4.91 & 3.86 & 3.95 \\
\hline & 3 & 5.97 & 6.21 & 4.56 & 4.79 & 3.77 & 3.87 \\
\hline & 4 & 6.28 & 6.52 & 4.83 & 4.95 & 3.93 & 4.11 \\
\hline & Mean & 6.11 & 6.48 & 4.77 & 4.94 & 3.83 & 3.96 \\
\hline \multirow{5}{*}{ Neck } & 1 & 6.01 & 6.13 & 4.56 & 4.65 & 3.06 & 3.47 \\
\hline & 2 & 6.13 & 6.37 & 4.19 & 4.59 & 3.13 & 3.28 \\
\hline & 3 & 6.03 & 6.49 & 4.16 & 4.76 & 2.94 & 3.13 \\
\hline & 4 & 5.86 & 6.21 & 4.53 & 4.73 & 3.17 & 3.61 \\
\hline & Mean & 6.01 & 6.30 & 4.36 & 4.68 & 3.07 & 3.37 \\
\hline \multirow[t]{5}{*}{ Thigh } & 1 & 6.22 & 6.77 & 5.09 & 5.21 & 4.11 & 4.33 \\
\hline & 2 & 6.40 & 6.62 & 5.00 & 5.36 & 4.01 & 4.18 \\
\hline & 3 & 6.61 & 6.86 & 5.21 & 5.50 & 4.15 & 4.35 \\
\hline & 4 & 6.01 & 7.11 & 5.18 & 5.61 & 3.97 & 4.01 \\
\hline & Mean & 6.31 & 6.84 & 5.12 & 5.42 & 4.06 & 4.22 \\
\hline
\end{tabular}

All counts are expressed in logarithms.

\section{Total coliform count}

The results showed that the mean values of the TCC of goat meat processed at slaughter yards of Koshaibari, Mymensingh Town and BAU campus was log 4.85 and that of delayed sample of goat meat sold in meat stalls was $\log 5.03$ (Table 1). The mean values of TCC in brisket, neck and thigh of goat meat processed at slaughter yards were $\log 4.77, \log 4.36$ and $\log 5.14$ respectively and $\log 5.94$, $\log 4.68$ and $\log 5.42$ respectively in delayed sample of goat meat sold in meat stalls (Table 2). Gill et al. (1998) showed that the meat contacting surfaces of cleaned equipment demonstrated less recovery of coliforms. The TCC of different body regions such as brisket, neck, and thigh are found to be $\log 4.94$, $\log 4.68$ and $\log 5.42$ respectively and the results are tabulated in Table 2. These findings have proximal relationship with the findings of Rahman et al. (1979). 


\section{Total staphylococcal count}

The result in Table 1 records that the mean value of the TSC of goat meat processed at slaughter yards of Koshaibari, Mymensingh Town and BAU campus is log 3.31 and that of TSC obtained from delayed sample of goat meat sold in meat stalls is log 3.82 (Table 1). The mean values of TSC in brisket, neck and thigh regions of goat meat processed at slaughter yards were $\log 3.83$, log 3.07 and $\log 4.06$ respectively and $\log 3.96$, $\log 3.37$ and $\log 4.22$ respectively in delayed sample of goat meat sold in meat stalls (Table 2). However, the highest count was recorded in samples of thigh site. The presence of Staphylococci in all the samples in such density indicated unacceptable hygienic standard particularly poor personal hygiene. Gracey and Collins (1992) noted that the meat product which was touched mostly by hands stood to be associated with reasonable changes of being inoculated with coagulase positive Staphylococci.

\section{Correlation between TVC, TCC and TSC}

A significant correlation $(\mathrm{p}<0.01)$ was found between the TVC and TCC but no significant correlation was found between TVC and TSC. However the report of Sankaran et al. (1975) did not agree with the present analysis. Correlation between TVC and TCC signifies that coliform count could be taken as an index of bacteriological quality of meat, but as there was not a significant correlation in TVC and TSC, so, counts of Staphylococci could not be a good index of bacteriological quality of meat though it is alarming. The variation of TVC in meats of different markets $(\mathrm{P}<0.01)$ and different carcass regions $(\mathrm{P}<0.05)$ is significant.

\section{Evaluation of sanitary quality of goat meat}

The result demonstrates the fact that the unhygienic and poor sanitary conditions under which the meat and meat products are handled and processed are not acceptable from sanitary point of view. It has further evidenced that the undesirable level of contamination which might have acquired from the environment and agents and to obtain wholesome, safe and sound meat, the principles of Longitudinally Integrated Safety Assurance (LISA) system and Good Manufacturing Practices (GMP) must be adopted.

\section{REFERENCES}

1. Bolton FJ, Crozier L and Williamson IK (1996). Isolation of E. coli 0157 from raw meat products. Letters in Applied Microbiology 23: 317-321.

2. Brahmbhatt MN and Anjaria JM (1991). Isolation of bacteria from market goat meat and their in vitro antibiotic sensitivity pattern. Indian Journal of Animal Science 63: 522-523.

3. Chowdhury SA and Mutalib A (2003). Goat production in Bangladesh present status and future programme. In: Goat production in SAARC countries, Afzal M and Usmani RH (eds). Pakistan Agricultural Research Council, Islamabad, Pakistan. pp. 6-28.

4. Dhanda JS (2001). Evaluation of crossbred goat genotypes for growth, carcass and meat quality characteristics. PhD Thesis, University of Queensland, Australia.

5. FAO (2001). FAO Production yearbook. Volume 55. FAO statistics series number 170. Food and Agricultural Organization, Rome. pp. 221-234.

6. Freed RD (1992). MSTAT Director. Crop and Soil Sciences Department, Michigan State University, USA.

7. Gill CO, McGinnis JC and Bryant J (1998). Microbiological contamination of meat during the skinning of beef carcass hindquarters at three slaughtering plants. International Journal of Food Microbiology 42: 175-184.

8. Gracey JF and Collins DS (1992). Meat Hygiene. 9th edn., Bailliere Tindall, London, UK. pp. 96-128.

9. Hassall J (1995). Bangladesh third livestock development project. Vol. 2. Meat Processing and Marketing Sector, Annexure 1: 1-46.

10. Hubbert WT, Hagstad HV, Hinton MH and Hughes KL (1996). Food Safety and Quality Assurance: Foods of Animals Origin. 2nd edn., Iowa State University Press, Ames, Iowa.

11. ICMSF (1985). Microorganism in foods; samples for Microbiological Analysis: Principles and specific applications. Recommendation of the International Commission on Microbiological Specification for Foods. Association of Microbiological Societies. Toronto, University of Toronto Press.

12. ISO (1995). Recommendation of the meeting of the subcommittee, International Organization for Standardization, on meat and meat products. ISO/TC-36/Sc-6. The Netherlands. 10-18 November 1995.

13. Jay JM (1978). Modern Food Microbiology. D. Van Norstrand Co., New York. pp. 116-123.

14. Johanson L, Underdal B, Grosland K, Whelehan OP and Roberts TA (1983). A survey of the hygienic quality of beef and pork carcasses in Norway. Acta Veterinaria Scandinavica 24: 11-13. 
15. Lasta JA, Rodriguez HR and Zanelli M (1992). Bacterial count from bovine carcasses as indicator of hygiene at slaughtering places. Journal of Food Protection 55: 271-278.

16. Rahman MA, Choudhury TIMFR and Rahman MM (1979). Microbial contamination of meat and their public health significance. Bangladesh Veterinary Journal 13: 1-7.

17. Rahman MM (2000). Fundamentals of Meat Hygiene. 'Bismillah’ Farming and Frozen Meat Ltd. Dhaka, Bangladesh. pp. 76-101.

18. Rahman MM, Rahman MH, Rahman MA, Haque AKMM and Islam N (1997). Microbial status and public health signification of goat meat sold in retail markets of Bangladesh. Progressive Agriculture 8: 121-124.

19. Samad MA (2001). "Pashu Palon O Chikitsavidya". $2^{\text {nd }}$ edn., LEP No. 09. Bangladesh Agricultural University Campus. Mymensingh, Bangladesh.

20. Sankaran R, Thangamani RK, Parihar BD and Nath H (1975). Microbial profiles of dehydrated cured mutton mince from raw material to the finished product. Journal of Food Protection 43: 135-140.

21. Sinha BK and Mandal LN (1977). Studies on bacteriological quality of market goat meat and its public health importance. Indian Journal of Animal Science 47: 478-481. 